Thorax (1974), 29, 389.

\title{
Early diagnosis of airways obstruction
}

\author{
G. M. C O C H R A N E, F. P R I E T O, B. H I C K E Y, \\ S. R. B E N A T A R, a n d T. J. H. C L A R K
}

Guy's Hospital, London SE1 and Brompton Hospital, London SW3

\begin{abstract}
Cochcrane, G.M., Prieto, F., Hickey, B., Benatar, S. R., and Clark, T. J.H. Thorax, 29, 389-393. Early diagnosis of airways obstruction. Three simple tests, maximum expiratory flow volume curve, maximum expiratory volume time curve and 'closing volume', were used to detect early airways obstruction in 21 smokers. A high proportion had abnormal values for $\mathrm{MEF}_{75} \%$, MEF $_{50} \%$, and FET $\left(86 \%, 71 \%\right.$, and $62 \%$ respectively) with a relatively normal FEV . There $^{2}$ was a good correlation between tests of small airways obstruction obtained from the forced expiratory manoeuvre. The measurement of 'closing volume' (phase 4/VC \%) was less satisfactory as there were difficulties with interpretation of the records in half of the studies. We conclude that the forced expiratory manoeuvre can be used to detect early airways obstruction as well as providing $\mathrm{FEV}_{1}$ and vital capacity.

The importance of early diagnosis of airways obstruction is not yet clear and further information is required about its natural history, and its relation to smoking habits and to the more advanced and less reversible stages of airways obstruction. It may be possible to use early detection to prevent the development of disabling chronic obstructive bronchitis.
\end{abstract}

Chronic airways obstruction is an important cause of ill-health in Great Britain. Treatment is frustrating because airways obstruction is usually advanced and irreversible by the time a patient complains of shortness of breath. The habit of cigarette smoking almost invariably accompanies this condition but not all smokers appear to be at risk and it might be helpful to identify those in whom airways obstruction was developing.

Work by other authors (McCarthy, Spencer, Greene, and Milic-Emili, 1972; McFadden and Linden, 1972; Buist, van Fleet, and Ross, 1973) has shown that smokers often give abnormal results in those tests which are believed to detect changes in the small airways. A group of cigarette smokers has therefore been used to investigate several of these tests to see which appear to be the most sensitive detectors of abnormality.

\section{SUBJECTS}

Twenty-one healthy men aged 21-66 (mean 36) years who had smoked from 3 to 140 (mean 23.4) pack years were studied (a pack year was defined as 20 cigarettes per day for one year). Six subjects produced $5 \mathrm{ml}$ of sputum per day, five others had throat clearing only, and the remainder gave no history of regular sputum production. None had suffered an upper respiratory tract infection in the last three months or complained of undue breathlessness on exertion.

\section{METHODS}

'Closing volume' measurements (Dollfuss, Milic-Emili, and Bates, 1967) were made by analysing the expired air following inhalation of a bolus of helium using a critical orifice helium analyser (Mead and Collier, 1959 ) in the manner described by Green and Travis (1972). Exhaled volume was measured with an Ohio 840 spirometer and recorded on the $X$ axis and expired helium concentration on the $\mathrm{Y}$ axis of a Tektronix $5103 \mathrm{~N}$ storage oscilloscope. Once dead space has been exhaled an alveolar plateau of helium concentration is achieved (phase 3 of expired air washout) and shortly before reaching residual volume airway closure begins as judged by a sudden and sustained change in helium concentration. The remaining lung volume above residual volume is known as the phase 4 and usually represents about $5-10 \%$ of the vital capacity. The 'closing volume' manoeuvre was carried out three to five times and the mean result was determined and expressed as the percentage of vital capacity occupied by the phase 4 volume (phase 4/VC\%).

An Ohio 840 differentiating spirometer was used to provide volume and flow signals during forced expiratory manoeuvres, and the flow-volume curves were recorded on a storage oscilloscope (Tektronix $5103 \mathrm{~N}$ ). A conventional timed expiratory volume curve was simultaneously recorded. The forced expiratory manoeuvre was repeated three to five times until three reproducible maximum expiratory flow volume curves were obtained and a mean of these measurements was derived. From 
the combined flow-volume and time-volume curves forced vital capacity (FVC), forced expiratory volume in 1 second $\left(\mathrm{FEV}_{1}\right), \mathrm{MEF}_{50} \%, \mathrm{MEF}_{75} \%$, and forced expired time (FET) were obtained. All volumes and flow rates were corrected to BTPS.

\section{RESULTS}

The results expressed as per cent predicted are shown in Figures 1 and 2. The predicted values for FVC, $\mathrm{FEV}_{1}, \mathrm{MEF}_{50} \%$, and $\mathrm{MEF}_{75} \%$ are taken from Cherniack and Raber (1972), for FET from the mean given by McFadden and Linden (1972), and phase $4 / \mathrm{VC} \%$ from the linear regression with age from Collins et al. (1973).

The range of results expressed as per cent predicted in the 21 smokers was FVC 78-138\%, FEV

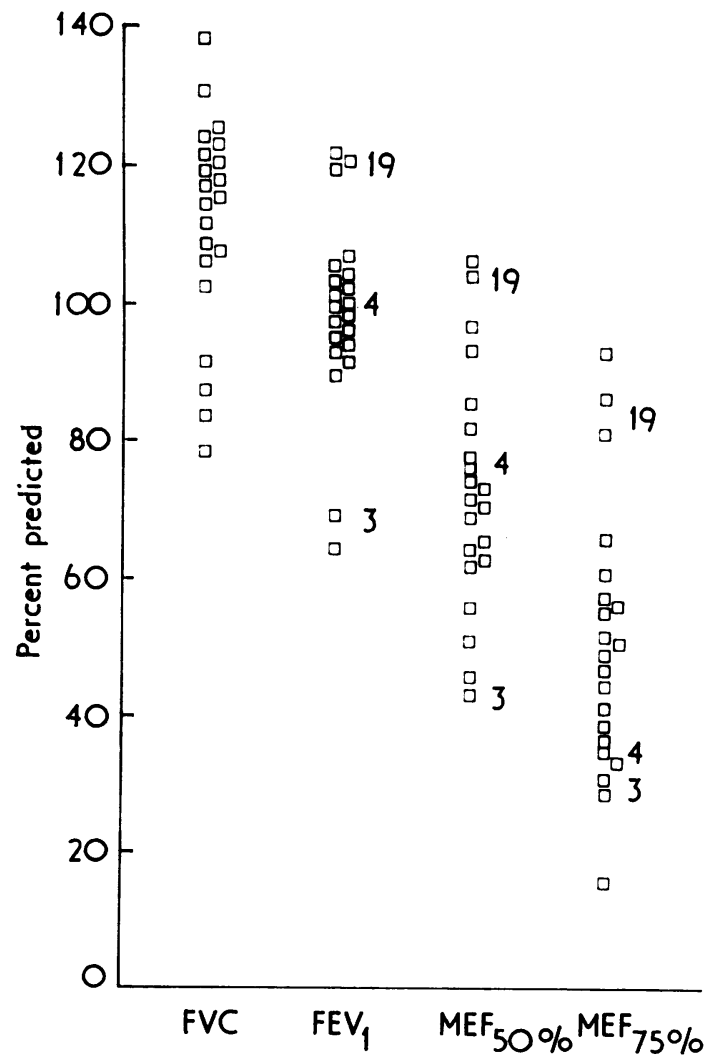

IIG. 1. Range of values obtained from the forced expiratory manoeuvre in smokers. The results in any single subject follow a consistent pattern: subject 19 has all values within normal limits; subject 3 has all values below predicted normal limits; subject 4 has a normal FEV but a $M E F_{50 \%}$ at the lower limit of normal and a $M E F_{75} \%$ below normal limits which suggests early airways obstruction.

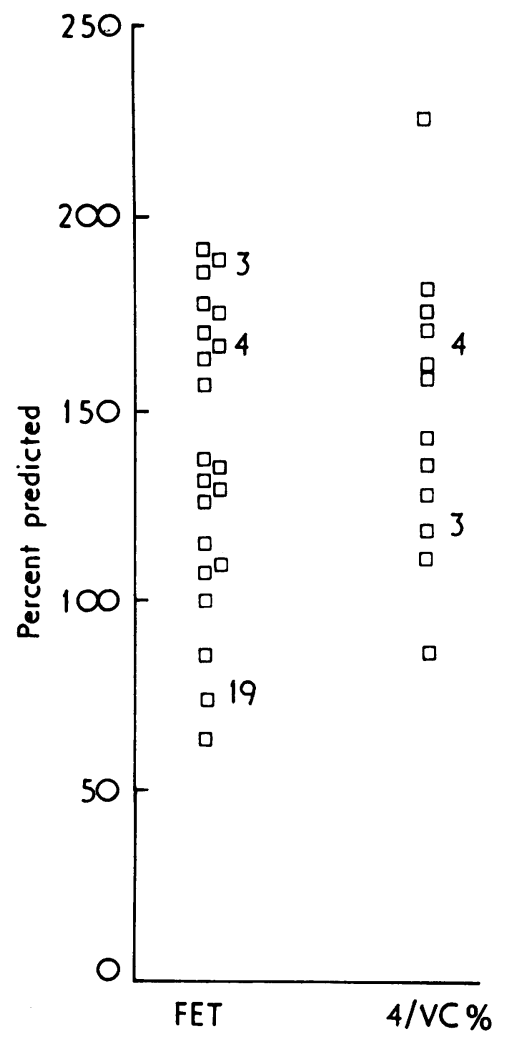

FIG. 2. Values for FET and for phase $4 / V C \%$ in smokers. Subject 3 has a normal phase $4 / V C \%$ although he had abnormal values for all measurements of forced expiration; subject 4 had abnormal FET and 4/VC\% which together with a low $M E F_{75} \%$ are suggestive of obstruction of small airways.

$64-121 \%, \mathrm{MEF}_{50} \% 51-106 \%, \mathrm{MEF}_{75} \% 16-93 \%$, FET $62-186 \%$, and phase $4 / \mathrm{VC} \%$ 0-230\%.

Despite the large range obtained for each value $D$ the results tended to follow a consistent pattern for any given individual. For example, all the measure- N ments obtained from a forced expiration in subject 3 were reduced to values below the mean of the normal values (see Fig. 1) while subject 19 showed no $\omega$ reduction in any measurement. By contrast, subject 2 4 had a normal $\mathrm{FEV}_{1}$ and $\mathrm{MEF}_{50 \%}$ but had a reduced $\varrho$ $\mathrm{MEF}_{75 \%}$ and an increased FET and 4/VC\% (Fig. 2) which is suggestive of small airways obstruction.

Only 12 smokers had interpretable 'closing to volume' traces (Fig. 2). Two others had traces with a $\underset{\mathbb{D}}{\stackrel{0}{*}}$

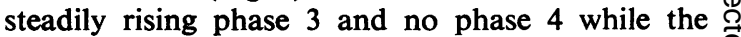
remaining seven had a horizontal alveolar plateau $\stackrel{\mathbb{D}}{\Omega}$ and no phase 4.

The results from this study of smoking individuals 
are compared in Fig. 3 with those from normal subjects and asymptomatic asthmatic patients with reduced $\mathrm{FEV}_{1}$ previously reported (Cochrane et al., 1974). The results of $M E F_{75}$ and FET for normal subjects compared with smoking subjects were significantly different $(\mathrm{P}<0.005)$. The 'closing volume' measurements made in the normal subjects and asthmatic patients were obtained using an inspired bolus of xenon-133, but Green, Travis, and Mead (1972) showed no significant difference between the 'closing volume' as measured by xenon and helium bolus techniques and this has been our experience.

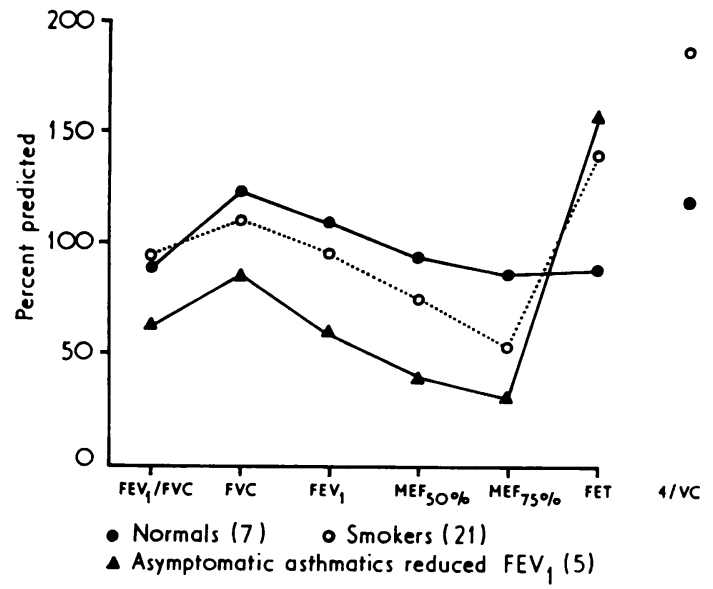

FIG. 3. Mean values expressed as per cent predicted in smokers compared with those of normals and patients with asymptomatic asthma; taken from Cochrane et al. (1974).

\section{DISCUSSION}

Chronic obstructive bronchitis causes widespread suffering and death, and early detection may identify those at risk at an early and possibly reversible stage. The most promising tests of early detection are 'closing volume' measurement (McCarthy et al., 1972) and measurements derived from a forced expiratory manoeuvre (McFadden and Linden, 1972; Cochrane et al., 1974). Closing volume measurements have been shown to be reproducible in normal subjects and are suitable for screening large numbers of persons for airways obstruction (Buist et al., 1973). The forced expiratory manoeuvre is easily learnt by patients, is familiar to physicians, and provides the $F E V_{1}$ and FVC in addition to the MEF $_{75} \%$ and FET.
SMOKING Of the 21 smokers, 18 had an $\mathrm{MEF}_{\mathbf{7 5} \%}$ below $80 \%$ of predicted; in 15 the $\mathrm{MEF}_{50} \%$ was reduced to less than $80 \%$ predicted; in 13 the FET was longer than $120 \%$ of predicted, and in eight of the 12 satisfactory measurements of phase $4 / \mathrm{VC} \%$ the result was above the $95 \%$ tolerance limits quoted by Collins et al. (1973). The correspondence between tests of small airway obstruction obtained from a forced expiration was close; all the subjects who had an abnormally prolonged FET had decreased $\mathrm{MEF}_{50 \%}$ and $\mathrm{MEF}_{75} \%$. While the majority of subjects thus showed evidence to suggest small airways obstruction, only two had an FEV kelow $_{1}$ $80 \%$ of the predicted mean value. All eight subjects with an abnormally increased phase $4 / \mathrm{VC} \%$ as well as both subjects with a steadily rising phase 3 and no phase 4 had abnormalities of the forced expiratory manoeuvre. One subject (subject 3, see Figs 1 and 2), however, had a reduced $\mathrm{FEV}_{1}$ with abnormal MEF $_{\mathbf{7 5} \%}$ and FET but displayed a horizontal phase 3 and no phase 4 , suggesting the possibility of false negatives if 'closing volume' measurements are used for detection. Our failure in half of the studies to achieve a satisfactory 'closing volume' trace also casts some doubt about its usefulness. In our study we found no consistent relationships between the number of pack years of smoking and a decreased $\mathrm{MEF}_{75} \%$ in contrast to Buist et al. (1973) who showed a positive correlation between total cigarette consumption and the frequency of abnormalities of phase $4 / \mathrm{VC} \%$.

Our results do not allow an estimate of prevalence of early airways obstruction in smokers nor can they accurately assess the degree of functional defect but this was not the purpose of our study which aimed to see whether the tests used could detect abnormality in healthy smokers and to compare the effectiveness of the tests in achieving this detection.

PROBLEMS ASSOCIATED WITH 'SENSITIVITY' AND 'NORMAL' VALUES Various normal ranges have been used by different groups of workers when comparing the sensitivity of tests of small airway function and this may explain why some workers (Buist et al., 1973; Solliday et al., 1973) have found "closing volume' measurements more sensitive than maximum expiratory flow volume curves.

According to our results, $\mathrm{MEF}_{75 \%}$ would appear to be the test most affected by small airways obstruction and is therefore the most discriminant test. Forced expiratory time is nearly as sensitive but is much cheaper to provide. These findings are in keeping with those of McFadden and De Groot (1973), and of Gelb and Zamel (1973); however, the sensitivity of $\mathrm{MEF}_{75 \%}$ may be in part caused by our 
use of the normal values quoted by Cherniack and Raber (1972) which come from a population living in a non-polluted area. The mean value for MEF $_{75 \%}$ for a small group of non-smoking healthy subjects living in London (Cochrane et al., 1974) was only $87 \%$ of that predicted by Cherniack and Raber (1972), suggesting that atmospheric pollution may reduce $\mathrm{MEF}_{75 \%}$. The sensitivity of $\mathrm{MEF}_{75} \%$ may also be caused by the expression of our results as the percentage of the mean predicted, and as Cherniack and Raber (1972) do not give confidence limits (although they mention that they determined the lower confidence limits of their multilinear regression equations) it is difficult to determine whether the mean values for our smokers were outside the scatter of normal values. Different normal values are also quoted in the literature for FET (Roy, Chapin, and Favre, 1955; McFadden and Linden, 1972), and if the mean FET of $2 \cdot 18$ seconds for men aged 20-39 is taken from Roy et al. (1955) FET becomes the most sensitive test of small airways obstruction in this study. From these considerations we feel that it is important to establish the normal mean and confidence limits for MEF $_{75 \%}$ and FET taking into account the influence of chest colds and urban environment.

Although the mean values obtained from our subjects who smoked were reduced compared with the normal values used in this study, there was much inter-subject variation even when expressed as per cent predicted. The intra-subject variation was small in all the measurements obtained from the MEFVC (less than $10 \%$ ) and similar to that reported by Green, Mead, Hoppin, and Wohl (1973); however, this range is artificially small as only apparently reproducible MEFVC curves were measured. The large inter-subject variation has been attributed to the more ready development of small airways obstruction in some subjects than in others. Takishima and Takahashi (1973) suggested that abnormalities of the terminal portion of the maximum expiratory flow volume curve and of the 'closing volume' trace are related to body size and shape. We could find no correlation between the Broca index (Broca index $=(\mathrm{wt}(\mathrm{kg}) / \mathrm{ht}(\mathrm{cm})-100)$ $\times 100$ ) and $\mathrm{MEF}_{75 \%}$, FET or 'closing volume' measurements.

CLINICAL RELEVANCE The prognostic implications of an abnormally reduced $\mathrm{MEF}_{75} \%$ or increased FET in the presence of a normal FEV $_{1}$ are not known and this is important as such abnormalities are found among asymptomatic smokers. Another important gap in our knowledge is the correlation between abnormal tests such as $\mathbf{M E F}_{75 \%}$ and pathological evidence of small airways obstruction but this information will be difficult to obtain. As the development of crippling irreversible airflow obstruction occurs in only a minority of smokers, this suggests that some are particularly at risk and these may be detected by demonstration of abnormal small airway behaviour at an early stage. Therefore the relationship between early airways obstruction which may be potentially reversible and the development of irreversible airflow obstruction needs to be more fully explored before the value of early detection of airways obstruction is established.

G.M.C. was supported by Sir Philip Oppemheimer's Friends of Guy's Fund and F.P. by Beca, General Abelardo Rodriguez (Mexico). B.H. was in receipt of a scholarship from the Association of Commonwealth Universities. S.R.B. was supported by the Board of Governors, National Heart and Chest Hospitals. We are grateful to Professor J. N. Hunt, Department of Physiology, Guy's Hospital for the loan of equipment; to C. Dexter and J. Copeland for technical assistance; and to Miss K. B. Henley for typing and preparing the manuscript.

\section{REFERENCES}

Buist, A. S., van Fleet, D. L., and Ross, B. B. (1973). A comparison of conventional spirometric tests and the test of closing volume in an emphysema screening center. American Review of Respiratory Diseases, 107, 735.

Cherniack, R. M. and Raber, M. B. (1972). Normal standards for ventilatory function using an automated wedge spirometer. American Review of Respiratory Diseases, 106, 38.

Cochrane, G. M., Benatar, S. R., Davis, J., Collins, $\underset{\mathbb{D}}{\times}$ J. V., and Clark, T. J. H. (1974). Correlation o between tests of small airway function. Thorax, 29, 172.

Collins, J. V., Clark, T. J. H., McHardy-Young, S., Cochrane, G. M., and Crawley, J. (1973). Closing volume in healthy non-smokers. British Journal of Diseases of the Chest, 67, 19.

Dollfuss, R. E., Milic-Emili, J., and Bates, D. V. (1967). Regional ventilation of the lung studied with boluses of 133 Xenon. Respiration $N$ Physiology, 2, 234. Gelb, A. F., and Zamel, N. (1973). Simplified diagnosis $N$
of small-airway obstruction. New England Journal of Medicine, 288, 395.

Green, M., Mead, J., Hoppin, F., and Wohl, M. E. 0 (1973). Analysis of the forced expiratory $\frac{\mathscr{C}}{\mathbb{D}}$ maneuver. Chest, 36, 33S.

- and Travis, D. M. (1972). A simplified closing- 7 volume method suitable for field use. Lancet, 2 , 905.

,-- , and Mead, J. (1972). A simple measure- $\frac{\AA}{\overparen{D}}$ ment of phase IV ('closing volume') using a @ critical orifice helium analyzer. Journal of Applied Physiology, 33, 827. 
McCarthy, D. S., Spencer, R., Greene, R., and MilicEmili, J. (1972). Measurement of 'closing volume' as a simple and sensitive test for early detection of small airway disease. American Journal of Medicine, 52, 747.

McFadden, E. R. and De Groot, W. J. (1973). An assessment of closing volumes and maximum mid-expiratory flow rates as tests of small airway disease. American Review of Respiratory Diseases, 107, 1102.

- and Linden, D. A. (1972). A reduction in maximum mid-expiratory flow rate. A spirographic manifestation of small airway disease. American Journal of Medicine, 52, 725.

Mead, J. and Collier, C. (1959). Relation of volume history of lungs to respiratory mechanics in anesthetised dogs. Journal of A pplied Physiology, 14, 669 .
Roy, J., Chapin, H. B., and Favre, J. (1955). Studies in pulmonary ventilatory function. 1. Vital capacity, first one-second capacity, and forced respiratory curves in patients with asthma: comparative evaluation of methods. Journal of Allergy, 26, 490.

Solliday, N. H., Solomon, D., Morse, S., Nam, K. Gracey, D., and Cugell, D. G. (1973). Airflow and closing volume measurements in early chronic respiratory disease. American Review of Respiratory Diseases, 107, 1103.

Takishima, T. and Takahashi, K. (1973). 'Closing volumes' and decreased maximum flow at low lung volumes in young subjects. Journal of Applied Physiology, 34, 188.

Requests for reprints to: Dr. G. M. Cochrane, Respiratory Function Unit, Guy's Hospital, St. Thomas Street, London SE1 9RT. 